\title{
TYPES OF NARCISSISTIC SELF-REGULATION IN THE CONTEXT OF PERSONAL FULFILLMENT
}

\author{
MARIA KLYMENKO \\ Ivan Franko National University of Lviv, \\ Universytetska st. 1, 79000 Lviv \\ E-mail address: mariia.klymenko93@gmail.com \\ ORCID number: https://orcid.org/0000-0001-5466-699X
}

\begin{abstract}
Aim. The aim of the research is to generalize different types of "healthy" narcissistic Self-regulation and to disclose the specific of self-fulfillment and personal life satisfaction.

Method. The empirical study involved 360 Ukrainian students $(\mathrm{N}=360)$, aged from 17 to 24 . The following research methods were used: F. W. Deneke and B. Hilgenstock's Narcissism Inventory (1989), A. Längle and C. Orgler's Scale of Existence (2003), E. Diener's Satisfaction with Life Scale (1985), D. Polhus and C. Williams's «Dark Triad of Personality» questionnaire (2002). The obtained data were processed by multivariate statistics (Statistica 8.0 and Exel), using cluster and comparative analysis (Student's t-test, Scheffe Test).

Results. The analysis shows that the most effectively functioning narcissistic selfregulation type is characterized by high narcissism that goes together with the high selfpower. The personal fulfillment indicators (such as: self-distance, self-transcendence, freedom, responsibility, existentialism, and personality) are also growing in such conditions. Adequate narcissistic self-regulation goes together with the more meaningful relations with reality and enrichment of the person's internal emotional life. With the growth of narcissism raises rather positive life acceptance and affirmative attitudes towards "Being" and oneself in it.

Conclusions. Narcissistic self-regulation is a mechanism that cares about the stability and integrity of the self-system, makes it possible to accept and appreciate one's own personality. Only through the prism of prizing oneself (high, but functional narcissism) the value of other people and the world could be seen. This opens the possibility to find and fulfill the meaning of existence.

Key words: narcissism, narcissistic self-regulation, self-system, personal fulfillment, satisfaction with life, self-value.
\end{abstract}

\section{INTRODUCTION}

7 his study is carried out in conditions of increasing individualistic society 1 orientations. The need to examine what affects subjective satisfaction with life and the general comprehension of the existence of modern people becomes 
also more considerable. Postmodern society's cultural transformation can be a subject for a psychological analysis as well. Individual narcissism is constantly growing. Even though it is supplemented with collective narcissism and higher individual self-esteem manifestation, that were limited by the different communities before (Bauman, 2005). This indicates special life queries, value orientations and needs to be focused on caring for personal well-being. Understanding personal interests, personal competence, achievements, competitiveness, «I am» personality, self-realization and self-fulfillment have become socially approved qualities and goals for people living in the XXI century. Adequate narcissistic self-regulation is the basic mechanism that integrates self-structure; it also cares about the experiences of its authenticity and sufficiently harmonious self-worth.

It was theoretically substantiated and empirically confirmed that different types of narcissistic self-regulation by crystallizing a specific personal self-value affect the ability to see values in the existence and to stay more existentially open (Klymenko, 2018). All dynamically conscious or unconscious elements of the self-system supported and regulated by a specific form of narcissistic self-regulation can give a person the opportunity to see the genuine meaning of life and existence, or, in the case of dysfunctional selfregulation, it may close horizons of possibilities by a curtain of psychological defenses (Klymenko, 2017b).

However, the question of "healthy" narcissistic self-regulation and its connection with meaningful existential actions requires an empirical study. It will probably give an opportunity to use this knowledge to understand and influence the subjective well-being of people. Also, it is significant to discover how individuals with different types of "healthy" narcissism perceive the world and see their relevant place in it. And how the actual meaning of life, selffulfillment have an impact on one's psychological state in general.

\section{ANALYSIS OF STUDIES AND PUBLICATIONS}

There always appeared the need to describe the normal forms of narcissism and its expediency as a parallel line for almost every study of the pathological forms manifestations. The problem of narcissistic self-regulation in terms of the psychological norm was investigated in the psychoanalysis paradigm. Z. Freud (1914), M. Klein (1945), K. Horney (1950), H. Kohut (1971), and O. Kernberg (1984) forrmulated the principal ideas of "healthy" narcissism, that are still in use and even didn't lose their relevance. For example: Heinz Kohut (1971) defined narcissistic Self-regulation as a mechanism that satisfies the normal needs of Self, is a required condition for the realization of creativity (a narcissistic deficit can give rise to problems with self-perception, self-disintegration, built a special narcissistic facade in contrast); Karen Horney (1950) also drew attention to the fact that narcissistic deficiency may lead to the development of its pathological forms (the possible reason could be found in specific 
childhood experience with a lack of empathy and unconditional love deficit); for Otto Friedmann Kernberg (2000) adequate narcissism is a constructive way of maintaining a relatively stable positive image of oneself and a ground for the adequate self-esteem and the manifestation of ambitions, inspiration, life senses, values, and ideals. The problem continued to be investigated in the writings of R. Raskin and H. Terry (1988), F. W. Deneke and B. Hilgenstock (1994), K. Morph and F. Rodewald (2001), J. Foster and W. Campbell (2003). K. Morph and F. Rodewald understand narcissistic Self-regulation as a holistic system of personal strategies that are determined by a communicational process and communicational situation, that are stimulated by the need for achievement in turn (Morf \& Rhodewalt, 2001); Robert Raskin, while forming the Narcissistic Personality Inventory (NPI), considered it from a healthy experience of oneself and adequate personal value to forms of strong personal pathology (Raskin \& Terry, 1988).

Most studies of narcissism are concentrated on the paradigm of psychoanalysis, using the terminology of Ego-psychology and object relations theory in particular.

This study is also focused on "healthy" forms of narcissism that can be measured in generalized conditions and within the applied psychology diagnostic competencies.

Personal self-fulfillment is basically studied in the existential psychology paradigm by V. Frankl (1946), R. May (1953), A. Längle (2002), I. Yalom (1980) and comes down to finding the meaning of life and openness to considerable existential values, going through the sensible, authentic, responsible life in general. And the question of self-fulfillment and implementation existence is deeply investigated in Ukrainian psychology as well. In works of T. Titarenko (2008), I. Gulyas (2011), I. Bolotnikova (2013) are investigated such problems as: living and "Being" in the world filled with meanings, internal self-fulfillment in terms of self-expression and self-perfection; the formation of man as integrated system and the productivity of self-development; self-building strategies (from the ability to see the pragmatic situational meanings to the prosocial personal orientation) on purpose to experience the highest spiritual life senses.

Unfortunately, there is no common term for self-fulfillment. It is often compared to self-realization and self-expression. It can be perceived as a separate or unifying phenomenon. In this exact article, the author is guided by the definition of self-fulfillment proposed in the framework of the existential psychology theory, which is discussed below.

\section{THEORETICAL RESEARCH RESULTS}

The narcissistic self-regulation (the phenomenon which functions on conscious and unconscious levels of the psychic apparatus) is a universal and specific system of self-regulation, aimed at protecting, fulfilling and preserving 
structural integrity, temporal stability, and a positive perception of oneself. Its tasks are to care about: sensory and physical needs; safety and confidence; stable self-esteem; assessment to life experience full of important senses and values. The narcissistic self-regulation supports the adequate orientation on new experience (new events, actions, thoughts, communication practices, etc.), satisfies the need in developing new possibilities and, as a result, new forms and methods of the unique personality expression (Deneke, 1994). It is also a way of maintaining the integrity of self-dynamism called "Self" in general. It is something that gives the core of our personality a sense of relative stability, even when there are destabilizing and threatening influences from the outside. The self-dynamism is a complicated and multifactorial phenomenon itself, which mostly works at an unconscious level and is formed of the personal experience basis (in terms of "approval/ disapproval" childhood experience) (Klymenko, 2018). It encourages acting in a special way to avoid disturbing affections and states of distress.

Normal narcissism is an adaptive way of self-esteem regulation. And the sense of personal value is a central element that indicates the effectiveness of the self-regulation mechanism. The loss of it, or vice versa, its extreme high deviation from reality options, informs about changes in the self-structure and destabilization in the work of self-regulation dynamism.

Summarizing: narcissism is a phenomenon that is regulated by one's Self. A constructive or destructive way of self-regulation is based on the whole life experience (everything that is affectively related to Self, everything that stimulates or supports the processes of narcissistic self-regulation in the self-system). Also, narcissistic self-regulation cares about a more positive affective balance, which influences on life satisfaction reflections. In this way, it supports higher self-esteem and a positive perception of oneself. In other words, narcissistic self-regulation can be called "healthy" narcissism, which exists in the adequate forms of self-regulating processes inside Self.

The self-fulfillment is the realization of the inner (spiritual) component of the personality (Gewirth, 1998): the discovering the Person such Alfrid Längle (2004, p. 5) calls the «free in man», as the ability to be oneself; the ability to see existential meanings and enable them to find feedback within one's feelings; the authenticity in relation to oneself and to the world; the ability to feel internal power, which cannot be literally explained; and the sense of responsibility as a necessary condition for an existential change (Längle, 2002). Since the meaning of life is the answer offered by life itself, then a person (by virtue of psychic and psychological peculiarities, experience and ideas, an active position, or passivity) can discard himself or herself in the existence of complete values, or ignore them (consciously or not) (Längle, 2002). The desire to be where the tangible value of life is, the will to feel its importance and the beauty of existence is the first step towards understanding the life meaning content. In this case, subjective satisfaction with life increases, conditions in which life proceeds become secondary and less significant. 
It should be noticed that in the context of existential psychology and A. Längle's (Längle, 2002) personal approach, such concepts as "existential fulfillment", "personal fulfillment" and simply "self-fulfillment" are used equivalently. It is always about the movement deep within own Self, the profound understanding of personal values, understanding life, overcoming contradictions of existence. The personal-existential dimension in the context of personality development.

Self-fulfillment is a state and process. The process of finding the identity and the vital content, and the state of an authentic fulfilled sense of the existence. It also implies existential antagonism: the alternation of openness to others and the restriction, selfless dedication to the world and the appropriation of something. All this is the alternation of external and internal, the alternation of acceptance and giving something away. The conditions the existential fulfillment in general are: the ability to «Be»; the feeling that life is good; possibility (personal right) to be yourself (Längle, 2011). The right to be yourself is a matter of self-worth and identity. If, however, a person has a lack of it, the search for the meaning of life can acquire the functions of psychological compensation. And the fundamental conditions of existence can be replaced. "I have the right to be" is the most important experience that will probably lead to the development of self-worth. The readiness for the existential Dialogue is a consequence of high self-worth (realizing personal self-value can open an individual's eyes on the appreciating and respecting of others). The person will be able to shift the focus of reflection from the Self to the surrounding world. The following questions arise as a result: "What are the most important tasks for me here? In what context do I stay? What has to be done?" And "I am ready to be here and see what this life proposes. I am ready to change my existence" - should be the right to answer when the self-awareness becomes fulfilled with life meanings and values (Längle, 2004). High self-worth makes Self stronger and is a condition for access to the deep spiritual dimension of the Person (Längle, 2011). It also makes possible to trust personal estimates, to defend Self against criticism of others and the destabilization that may come from the environment.

A. Längle referring to V. Frankl's (Längle, Orgler, \& Kundi, 2003) emphasized that the deepest human motivation is the search for meaning. The lack of motivation combined with a sense of emptiness and meaninglessness may lead to an existential vacuum that has an impact on the development of all neuroses. In general, the whole path to existential fulfillment begins from the acceptance of the world as it is, acceptance of oneself being an important subject of existence. Actually, self-value is a considerable phenomenon than unifies both narcissistic self-regulation and self-fulfillment. The direct task of narcissistic self-regulation is to maintain a positive perception of oneself, a sense of self-value, and the whole personality integration. In the case when narcissistic self-regulation performs harmoniously - the existential change becomes possible. 


\section{EMPIRICAL RESEARCH RESULTS}

\section{Method}

An empirical study was carried out to objectify the peculiarities of personal self-fulfillment under the conditions of various types of narcissistic self-regulation. The empirical research involved 360 Ukrainian students $(\mathrm{N}=360)$, aged from 17 to 24 (adolescent and early adulthood periods). For the sample group of the study were selected individuals are actively passing the period of personal formation and for whom questions of existential fulfillment become urgent (Erikson, 1968). Also, personal self-esteem should be already crystallized and relatively stable. All data were processed by methods of multivariate statistics using cluster and comparative analysis (Student's t-test and Scheffe Test).

Proceeding to the statistical processing cluster analysis has been used to process primary results in order to distinguish different types of narcissistic self-regulation, and then analyzing the statistical differences of the mean indictors via Scheffe Test. Also, the classification was carried out on standardized data, provided with normal distribution. Tree blocks of clusters were isolated on the basis of the F. W. Deneke and B. Hilgenstock's Narcissism Inventory (1989) by the "Tree of clusterization" method. Such scales involved: self-weakness, loss on control on emotions, depersonalization/ derealization, hope potential, negligible Self, negative body image, social isolation, archaic care, self-grandiosity, ideal Self object, desire for praise, narcissistic rage, self-sufficiency, depreciation of others, ideal of values, need for protective symbiosis, hypochondria and benefits from illness. All scales reflect the features of self-regulation, general self-power and the level of narcissism in the measurement of self-worth. Using the clustering method "k-medium" then, three corresponding clusters were grouped together. Thus, the first cluster included 127 people (35\% of the sample), the second -106 ( $30 \%$ of the sample) and the third - 127 (35\% of the sample) (Fig. 1). The distribution correctness is higher than $90 \%$.

All three clusters were compared by the averages of every scale of F.W. Deneke and B. Hilgenstock's Narcissism Inventory (1989) and profiles depicted in Figure 1 where built. The profile analysis was completed on the basis of fixing the differences between obtained average indicators and such indicators that are inherent for the ideally strong Self that is provided in the research methodology of F. W. Deneke and B. Hilgenstock's Narcissism Inventory (1989). The indicator of a perfectly strong Self is zero (self-index $=0$ ). So the closer to zero is, the average self-index in each cluster, the more effectively self-regulation functions. The narcissism is also analyzed in a similar way: an ideal indicator of narcissism is 8 . And only that narcissism can be considered as functional as it is accompanied by high efficiency of Self. 


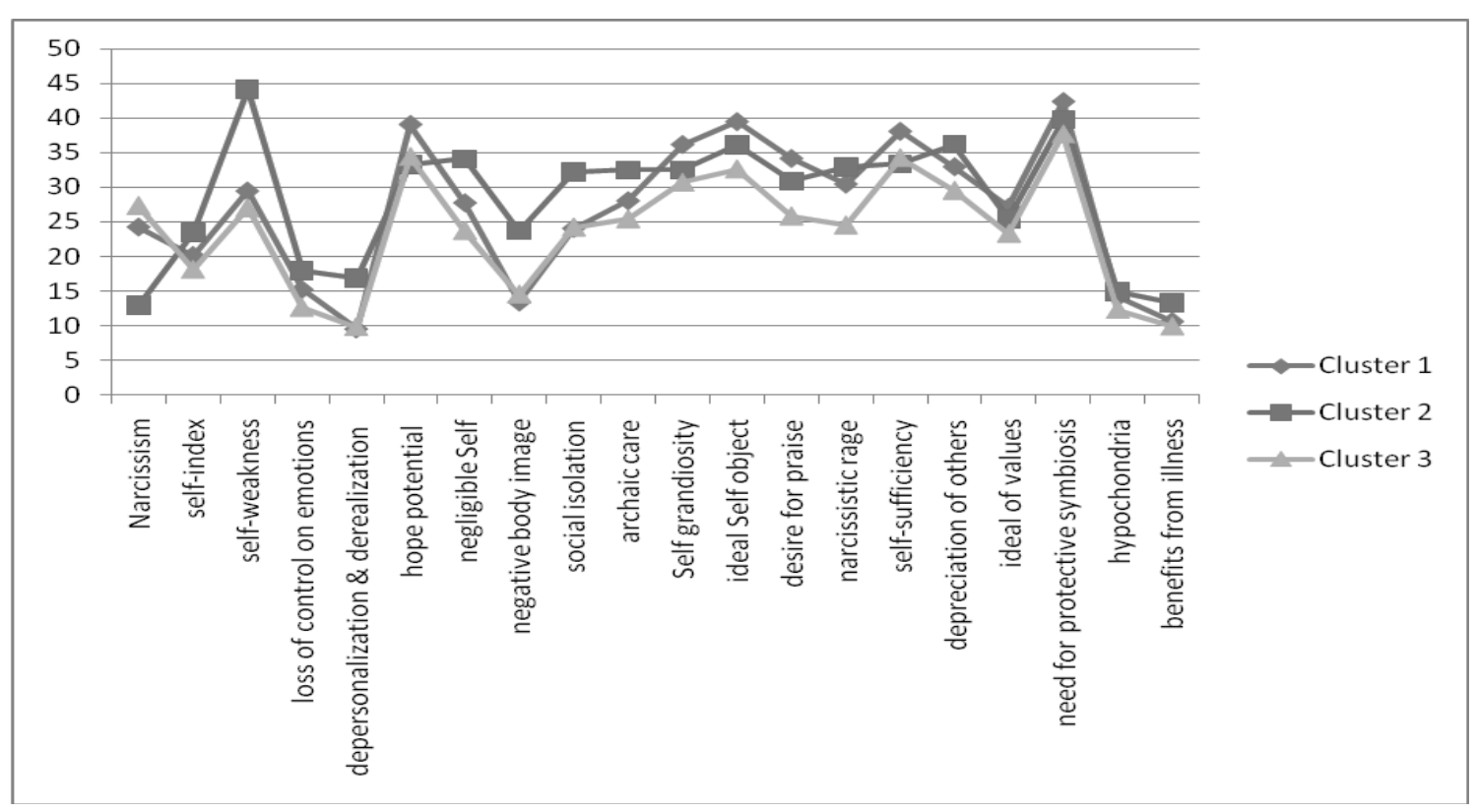

Figure 1.

The defined narcissistic self-regulation types (cluster analysis).

Source: own research.

To study features of personal fulfillment depending on different types of narcissistic self-regulation A. Längle and C. Orgler's Scale of Existence (2003) was used. Self-distance self-transcendence, freedom, responsibility, Person and Existence (Längle, 2002) - are such exact scales, that according to the methodology of existential psychology, give complete information on the meaningfulness of life (Längle, Orgler \& Kundi, 2003). It was accompanied by studying life satisfaction via E. Diener's Satisfaction with Life Scale (1985). Also, the manifestations of Dark Triad traits were investigated depending on how the self-regulation functions. The differences between distinct types of narcissistic self-regulation in terms of predisposition to Machiavellianism, Narcissism and Psychopathy were measured by D. Polhus and C. Williams's "Dark Triad of Personality" questionnaire (2002). The purpose of choosing the last method is the investigation of narcissism, not only from the self-regulation point of view, but also as a manifestation of a trait (the behavioral manifestation). And the Dark Triad is a complex of traits that inevitably correlate with one another.

To compare the considerable differences between types of the narcissistic self-regulation and the specified parameters of self-fulfillment the Scheffe Test was used. And to clarify the disparity between the two most polar types of selfregulation in terms of personal fulfillment, life satisfaction and manifestations of Dark Triad traits the Student's t-test was used likewise. All statistical studies were provided with the tested homogeneous dispersion. 


\section{DESCRIPTION OF NARCISSISTIC SELF-REGULATION TYPES}

Three types of narcissistic self-regulation were singled out. Cluster 1 implies high narcissism in combination with moderate integration of Self; cluster 2 points out the lowest narcissism that goes together with the most dysfunctional and disintegrated Self; cluster 3 indicates the highest narcissism combined with the most constructively functioning Self (Fig. 1).

The following qualitative description of the narcissistic self-regulation types is based on cluster analysis and descriptive statistics.

The first type (cluster 1), "High narcissism in combination with moderate integration of Self" (Fig. 1), is characterized by:

The average power of Self; the moderate loss of control over emotions and aspirations; the reduced tendency to experience depersonalization and derealization (such kind protections against misbalancing influences); the high base of potential hope; the reduced feeling of insignificance; the most positive representation of own body; the minor experience of social isolation; a moderate manifestation of the need for archaic care, as an unconscious regression and desire for detachment from the world of public, culture and technology; the highest expression of personal grandiosity; the significant desire to have the ideal self-object (and fantasy that this narcissistic self-object has to protect and inspire); the great desire for praise; the slight predisposition to a narcissistic rage; the highest self-sufficiency; moderate predisposition to devaluation; high values of personal senses; the overwhelming need for the symbiotic protection of Self (in merging with an internalized object that may give a sense of security); inherent to a strong Self usage of hypochondria as anxiety protection and very weak tendency having narcissistic benefits in the disease.

The second type (cluster 3), "Low narcissism in combination with dysfunctional and disintegrated Self" (Fig. 1), is characterized by:

The strongest weakness of Self (as tangible personal impotence); the significant inclination to lose control over emotions and aspirations; a significant propensity to derealization/ depersonalization (as unconscious coping strategies in situations that could be threatening for personal stability and self-worth); the lowest potential of basic hope; the hardest feeling of insignificance; the most negative perception of own body; the strongest feeling of social isolation; the significant need to escape from reality, because the last can cause a sense of anxiety and a certain threat; some kind of reduced sense of personal grandiosity; the strong desire to find an object that is strong enough, internalize it then, keep it at the level of fantasies and receive protection; the constant desire for praise; the highest inclination to the narcissistic rage; the low self-sufficiency; the significant tendency to depreciate others and the world around; the presence of value ideals, but their certain superficiality; the overpriced need for Self to be symbiotically merged with another object; a slight tendency to use hypochondria as anxiety protection, and not really significant illnesses to explain personal failures. 
The third type (cluster 2), "High Narcissism in combination with constructively functioning and the most integrated Self" (Fig. 1), is characterized by:

The greatest strength of Self and its own significance; the slightest tendency to lose control over emotions and aspirations; less tendency to use depersonalization and derealization; a moderate indicator of the basic hope potential; more positive view on the body itself and the highest capacity to detoxify negative moments so that they do not have an impact on self-esteem; the highest potential of communicability and the lowest social avoidance; insignificant need to escape from interaction with real world; not extremely declared Self grandiosity (which indicates that such a high narcissism is functional and nonpathological); moderate desire to have an ideal self-defending object; adequate desire for praise; the lowest predisposition to the narcissistic rage manifestations; the highest sense of self-sufficiency, such as personal responsibility and orientation towards the achievement of life goals; the highest tolerance in communication and the lowest criticism if something goes not as it was expected; the presence of life ideals, that are helping to built a meaningful existence, but also there are some doubts about them (can be assumed that this is due to the age of peculiarities in the sample group); certain need for the symbiotic protection of Self (to find somebody, who is inspiring, showing a charisma, having influence on people); the slightest tendency to escape into the state of hypochondria, in order to protect oneself from anxiety and less need to explain life dissatisfactions with the own body limitations.

From Figure 1 can be also concluded that those three distinct types of narcissistic self-regulation, apart from the investigated scales, differ in terms of integrative indicators: narcissism and self-index (the strength of Self and also the main indicator that shows how the narcissistic self-regulation functions). The data were also confirmed by comparing every mean of integrative indicators in three examined clusters using Scheffe Test. Found significant statistical differences are shown in the table below (Tab. 1).

Table 1.

Statistical differences between integrative indicators of narcissistic self-regulation in every cluster.

Comparison of significant differences between every cluster mean of integrative indicators (1:2:3); $p<0.05$

\begin{tabular}{lccccccc}
\hline & 1 & 2 & 1 & 3 & 2 & 3 & $\mathrm{p}$ \\
\hline Narcissism & 24.3 & 12.9 & - & - & 12.9 & 27.3 & 0.00 \\
\hline Self-index & 20.2 & 23.5 & 20.2 & 18.2 & 23.5 & 18.2 & 0.00 \\
\hline
\end{tabular}

Source: own research.

So, the data in Table 1 confirmed the qualitative analysis of the types of narcissistic self-regulation (described above) and captures the link between the effectiveness of self-regulation and the rise of narcissism, which in such circumstances can be actually healthy. 


\section{PERSONAL SELF-FULFILLMENT DIFFERENCES DEPENDING ON THE FUNCTIONING OF NARCISSISTIC SELF-REGULATION}

The statistical differences between the two most qualitatively polar types (with the highest narcissism and the most constructively functioning Self and the profile with the lowest narcissism and most dysfunctional Self) are analyzed in the article. Described results were identified via Student's t-test and all of them indicate only significant statistical differences. It is worth noting that comparative analysis revealed differences across all, without exception, indicators of personal fulfillment and life satisfaction.

Therefore, the following diversities were recorded:

1. The group with the highest narcissism and the most "healthy" selffunction type is characterized by the highest satisfaction with life ( $\mathrm{t}$-value $=5.69$; $\mathrm{p}=0.00)$ (Fig. 2).

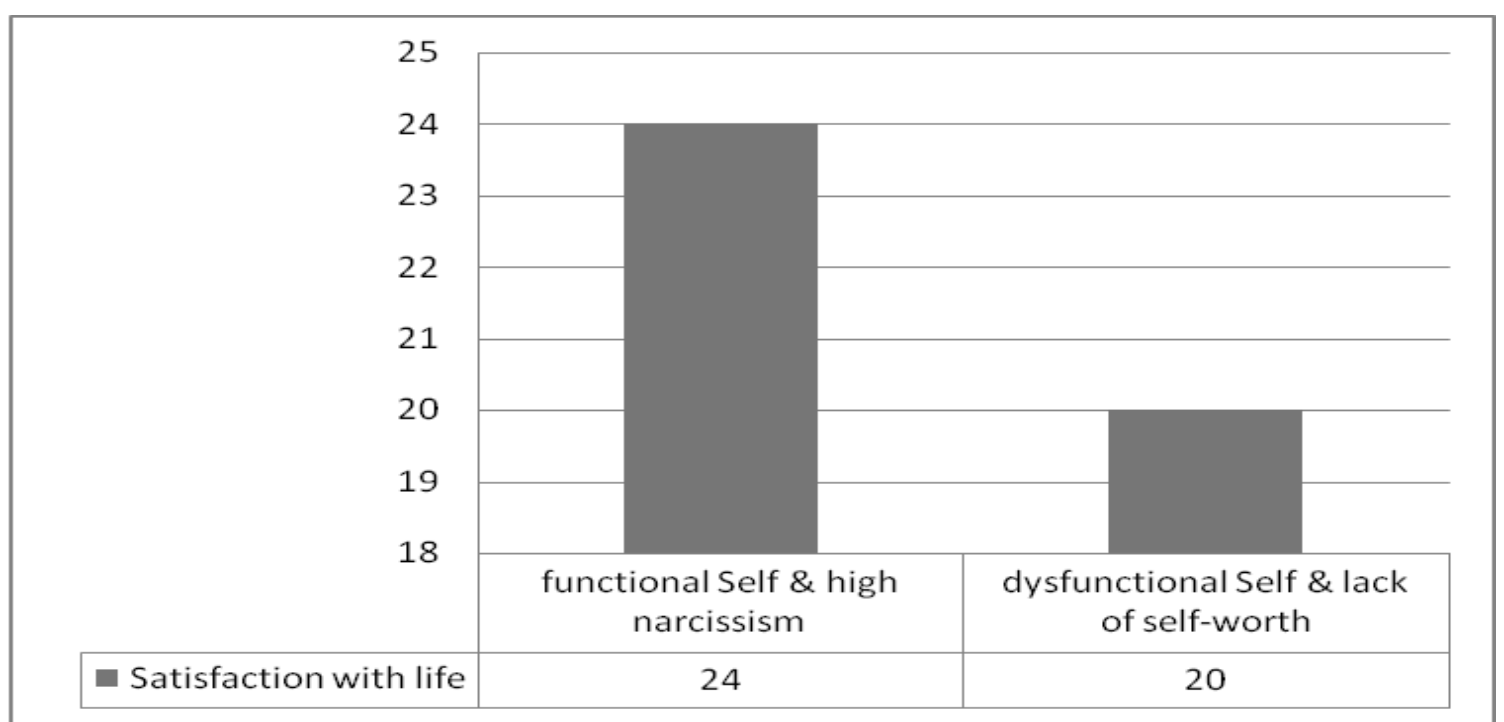

\section{Figure 2.}

Graphic depiction of satisfaction with life of distinct narcissistic self-regulation types.

Source: own research.

Life satisfaction is a cognitive and emotional way to assess reality (Diener, Sandvik, Seidlitz \& Diener, 1993). It is a personal reflection on life conditions that can be the same for several individuals, but for different people variously valued (Vasudha \& Prasad, 2017). Ed Diener, Ed Sandvik, Larry Seidlitz, and Marissa Diener through the analysis in a joint article (1993) understand this phenomenon as the predominance of positive or negative emotions on the scale of emotional evaluation of one's life itself. Accordingly, the worse the narcissistic self-regulation functions (which is directly responsible for maintaining an emotional balance in terms of feelings of internal stability, self-esteem, self-confidence, self-efficacy and good 
mental health in general) the lower the assessment of the one's Self and, as a result, his/her life is. In this case, adequately high narcissism may be a predisposition for the higher level of well-being and the openness to positive affective stimulation of life.

2. The "unhealthy" narcissistic self-regulation type (low level of narcissism and the strongly disintegrated Self) is characterized by a degraded level of general self-fulfillment, as a living of meaningful life overall rate indicator $(\mathrm{t}$-value $=11.5 ; \mathrm{p}=0.00)$ (Fig. 3). This points out the significant distance from Person: self-concentration and low ability to the establishment of a constructive dialogue with the outside world. For such people, life is perceived more as unfulfilled, characterized by a lack of sense and the ability to see values and allow them "attracting" themselves. It can be assumed that there is a long or temporary existential vacuum. In the case of low narcissism and Self disintegration, which uses a large amount of mental defenses in the struggle for psycho-emotional stability, there possibly could be the living of such life that is perceived as meaningless and deprived of value. This markedly differs from what we can see in the group with high narcissism and integrated Self. Such individuals are more committed to the process of self-fulfillment; there is a growing inner openness; a deeper knowledge about how to treat themselves and the world which occurs. They do feel an authentic process of implementing life's plans. The general indicator of self-fulfillment gives the information about the ability of individuals who belong to a certain profile of narcissistic self-regulation to cooperate with themselves and the world; the potentiality in the personal wisdom how to relate to the requirements of responsibilities internally and externally. In this context, the meaning of life is not borrowed and therefore does not feel like something which is not personally yours but rather authentic and important. The self-regulation that functions more effectively, builds the connection with the growth of personal fulfillment, comprehension of life, ability to perceive, feel, choose, decide and act. This is a way to separate yourself from others more realistically (see yourself from the side, realize your individual value). It is also about the ability to enable the values from outside to touch your personality, to understand what causes resonance in the soul and deep apprehension of the personal responsibility in the process of internalization of the values offered by the world. And also this is not only an opportunity to choose but to take liberty for the choice realization. Finally, it is the willingness to carry existential responsibility for life-making decisions and actions, to preserve the internal ideal of values. And the most important step in the comprehension of existential fulfillnes (in order to feel the happiness from the whole process) is the step of the incarnation of the found meaning through the best-allowed opportunity. 


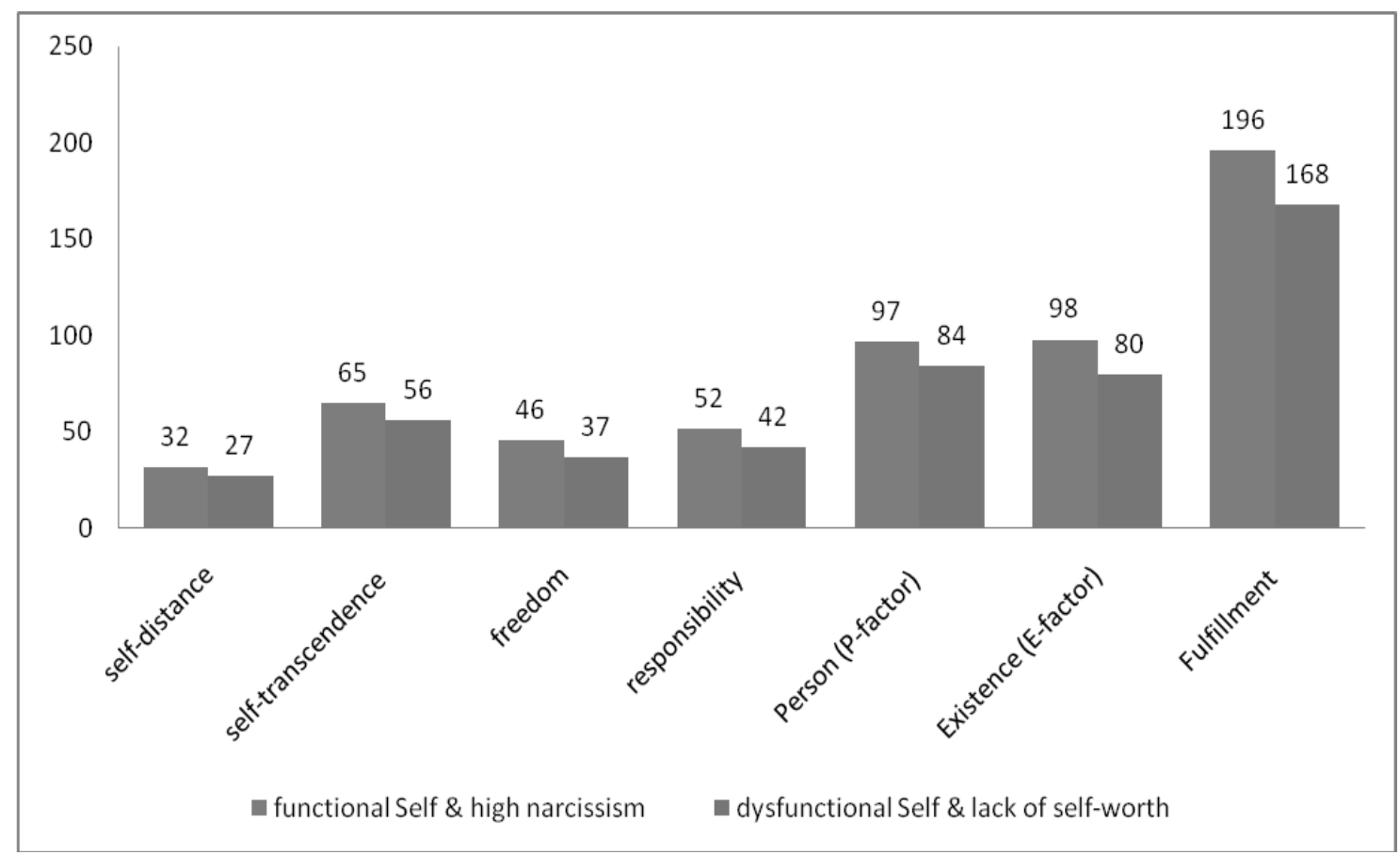

Figure 3.

Graphic depiction of existential fulfillment of distinct narcissistic self-regulation types.

Source: own research.

3. All self-fulfillment indicators decrease in a group with the worse functioning narcissistic self-regulation; and vice versa: functional narcissistic selfregulation is combined with the experience of personal self-fulfillment as more relevant and considerably higher. Describing in details:

a) The most dysfunctional type of narcissistic self-regulation represents a poorly developed ability to build an adequate self-distance ( $\mathrm{t}$-value=7.14; $\mathrm{p}=0.00$ ) (Fig. 3). This indicates an imbalance in the internal personal space. But this internal space is extremely important for developing the ability to appreciate values (full of meanings) that can be discovered in the outside world. Too much impulsive behavior (a quick reaction to irritants, dependence on them) may testify the small distance in relation to the personal Self. It shows the inability to look at oneself from the side. This may lead to the dissociation of "healthy" parts of Self from potentially threatening and destabilizing elements within, in order to preserve the integrity of the personal structure. But for a strong Self, the depersonalization/derealization type of perception of oneself and the environment is accurately less typical. From the above, the franked acceptance of what is happening to him or her can be seen.

b) The decrease in self-transcendence ( $\mathrm{t}$-value $=8.01 ; \mathrm{p}=0.00$ ) for a less constructive narcissistic self-regulation functioning type was recorded (Fig. 3). This suggests a greater emotional simplicity (perhaps even poverty) in relations with people, the world and "Being". In that case the values of the world have little to do with personal feelings. But, in fact, exactly with the help of 
them, the human establishes a connection with what can give sense to existence. When the harmonious type of narcissistic self-regulation reveals, it is accompanied by a greater enrichment of the emotional sphere and personal openness to values. Thus narcissistic self-regulation gratifies the needs of Self in the new experience, in new feelings, in new ways of self-expression, cares about the ability to feel values, to be emotionally "affected" by them. "Will to meaning" as our primary existential motivation is very emotional in its definition. Only through the touch to our feelings, we can live authentically and freely by finding the essence in the midst of inner and outer reality.

c) The profile with a low narcissism and least efficient self-regulating strategies is connected with a low level of personal freedom ( $t$-value $=10.03 ; p=0.00)$ as an existential measurement of the ability to make a personalized choice (Fig. 3). It is also the ability to see space for different opportunities, to act meaningfully and have a will to change the nearest reality (Fig. 3). It shows the indecisiveness and sense of insecurity of individuals, when one's Self suffers from imbalances. And conversely, the profile with the highest narcissism and the most effectively functioning narcissistic self-regulation is characterized by greater freedom in the decision-making. That is, the ability to be so called "decisive human" is connected with the self-strength and self-worth. The actual way of the self-freedom realization should be passing through the ability to notice existential opportunities in every important situation. And the ability to choose something (from the full spectrum of possibilities) will definitely open up afterwards.

d) The stronger integrated Self and high narcissism are connected with a growth of personal responsibility ( $\mathrm{t}$-value $=9.69 ; \mathrm{p}=0.00)$, which is a prerequisite for a meaningful existence in the world of values (Fig. 3). This is an existential sense of duty, an ability to make a decision on the basis of personal value, personal "inclusiveness" in life. A. Längle ( 2002) points out that adequate responsibility could be the basis for the formation of self-esteem. Also, it could be consequential for its maintaining at a high level. However, can be assumed that the self-esteem and responsibility, of a certain kind, are mutually dependent. Well-organized Self (does not suffer from «breaking» impulses, which are hidden by psychological protections) and integrative narcissistic self-regulation maintain a high, healthy self-esteem, take care of a general sense of self-worth, which is a prerequisite for the ability to trust oneself, "withstand» decision, be faithful and feel the internal resources. The loss of self-efficacy (observed in the profile with less effective narcissistic self-regulation) informs about the weakness, senses of inner impotence and emptiness. Thereby Self tries to protect the internal value with all possible efforts.

e) For a profile with more functional narcissism, the growth of self-awareness as a Person (existential Ego and existential dimension of human beings, which makes them feel their Person (Längle, Orgler \& Kundi, 2003) is characteristic ( $t$-value $=9.25 ; p=0.00)$ (Fig. 3). It testifies to the more existentially open perception of the world and the Self. The growing of Personality (disclosure of Person, "the existential meaning in me") is the discovery of "Being". It can 
be seen as the lowest level of this parameter in a profile with dysfunctional narcissistic self-regulation instead. This may indicate a significant blockage of basic personal abilities, isolation, possible personal immaturity or longterm experience of complex internal conflicts (neuroses may be). The narcissistic self-regulation should integrate those things mentioned above into the normal experience of one's Self, using protective mechanisms such as derealization/depersonalization, depreciation and escape from reality. Low Personality can also give rise to some reactions of somatization. This can manifest itself (as we can see from the characteristics of narcissistic self-regulation types above) in signs of the bad attitude towards own body, hypochondria, unconscious escape into illness. This is an important conclusion, because the concept of human entity is a confluence of the somatic, psychic and spiritual dimension in the theory of existential fulfillment (Längle, Orgler \& Kundi, 2003).

f) The more effective narcissistic self-regulation goes together with the growing personal existentiality ( $\mathrm{t}$-value $=10.87 ; \mathrm{p}=0.00$ ) (Fig. 3 ). It is an ability to enter the world confidently and responsibly. The profile with reduced narcissism and dysfunctional Self is characterized by difficulties in making life decisions instead. Persons with low narcissism are very unsure of their desires, needs, and, as a consequence, decisions. There is no certainty whether they really take their own «place» in their word and live a unique life. This is a sign of difficulties in the sense of personal authenticity. Thus the ability to withstand life's problems, coordinate actions with internal existential guidelines, feel their value and importance of the world as well are reduced. In a group where the narcissistic self-regulation cares about self-integration, there is an increase in vitality, the existence becomes more authentic, holistic and perceived in the context of elections and responsibility. One can speak of the presence of the personal existential living space and the desire to "be in the world" (Längle, 2004), see and feel the values. Such individuals are more able to stay in a dialogical exchange with the world and feel more naturally in tolerating life values that may influence on self-perception (Klymenko, 2018).

\section{THE MANIFESTATION OF DARK TRIAD TRAITS IN CONNEC- TION WITH NARCISSISTIC SELF-REGULATION}

It is also important to describe what differences have been found at the Machiavellianism and Psychopathy personal traits manifestations. These traits were studied in non-pathological ranges using the Dark Triad personality test (Paulhus \& Williams, 2002). A comparative analysis was also carried out using Student's t-test and all the differences are statistically significant.

So, it was found that for the profile with high narcissism and more stable Self, the use of manipulative tendencies in interpersonal interaction is less common: lower Machiavellianism ( $\mathrm{t}$-value $=-5.1$; $\mathrm{p}=0.000001$ ) as a personality trait (Fig. 4). 


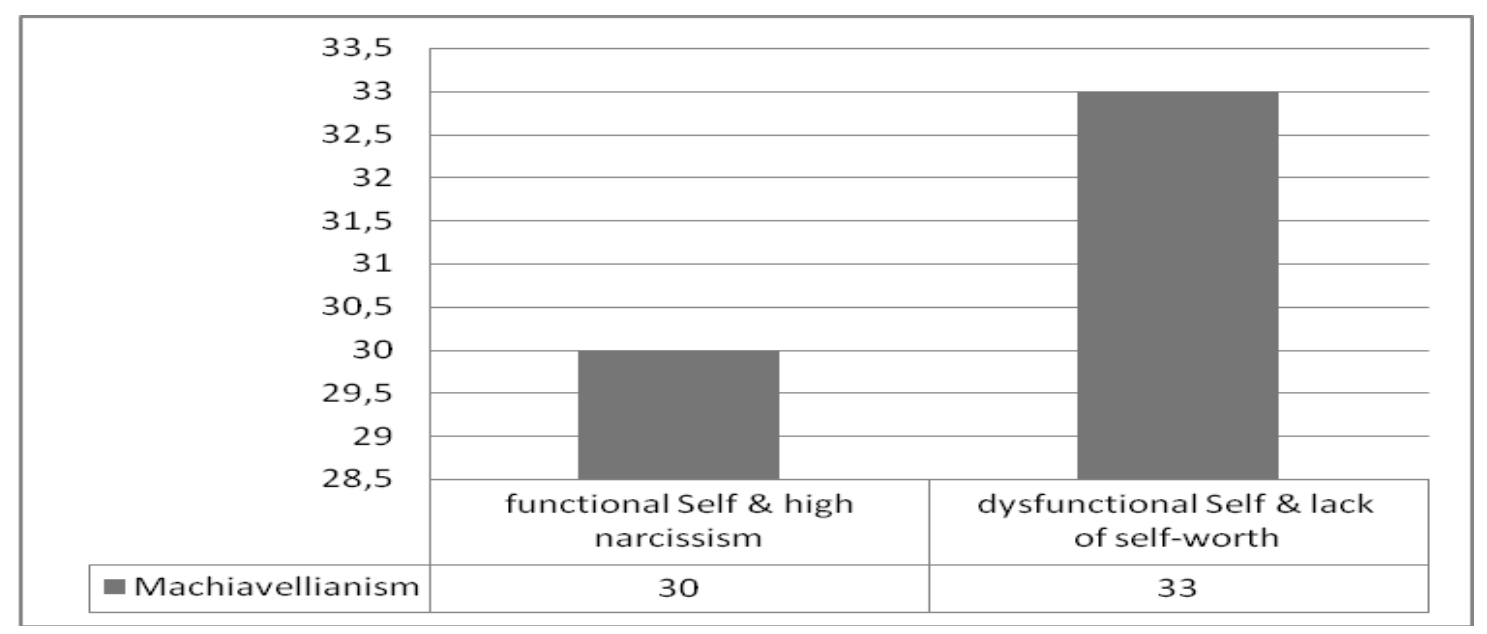

Figure 4.

The propensity for Machiavellianism, depending on the type of narcissistic self-regulation.

Source: own research.

Persons with lower narcissism and weaker Self are more prone to: focus only on their ambitions and interests; give preference to material values than to spiritual ones; use others to achieve personal goals; have a low empathy; demonstrate fictitious values and conceal the actual ones; avoid social relations that can cause attachment; have closed attitudes towards the world in their behavior and cognitive representations. Although such individuals can overcome the situation of competition more effectively, evaluate social situations and reactions better, the tendency to "selfish" behavior can indicate a "tunneled" type of the observation of world values (Klymenko, 2017a) diminished morality and responsibility, combined with uncertainty in oneself, low self-value and reduced satisfaction with life, weak life-senses orientations. In a combination with the self-weakness, there is a significant tendency to devaluation, a growing sense of social isolation, a significant need for praise, and narcissistic rage manifest. The tendency to behave like a Machiavellian can be a way of neurotic protection, competing for self-worth (self-affirmation at the expense of others) with the help of negation of personality parts that interfere with the harmonious Self-functioning.

In the case of dysfunctional Self and reduced narcissism, the psychopathic index ( $\mathrm{t}$-value $=-5.08 ; \mathrm{p}=0.000001$ ) also increases (as a non-clinical personality trait) (Fig. 5), which implies: fearlessness, low anxiety, reduced sense of responsibility, predisposition to antisocial behavior (in certain cases), self-absorption, some poverty of the emotional sphere, lack of empathy (Paulhus \& Williams, 2002). 


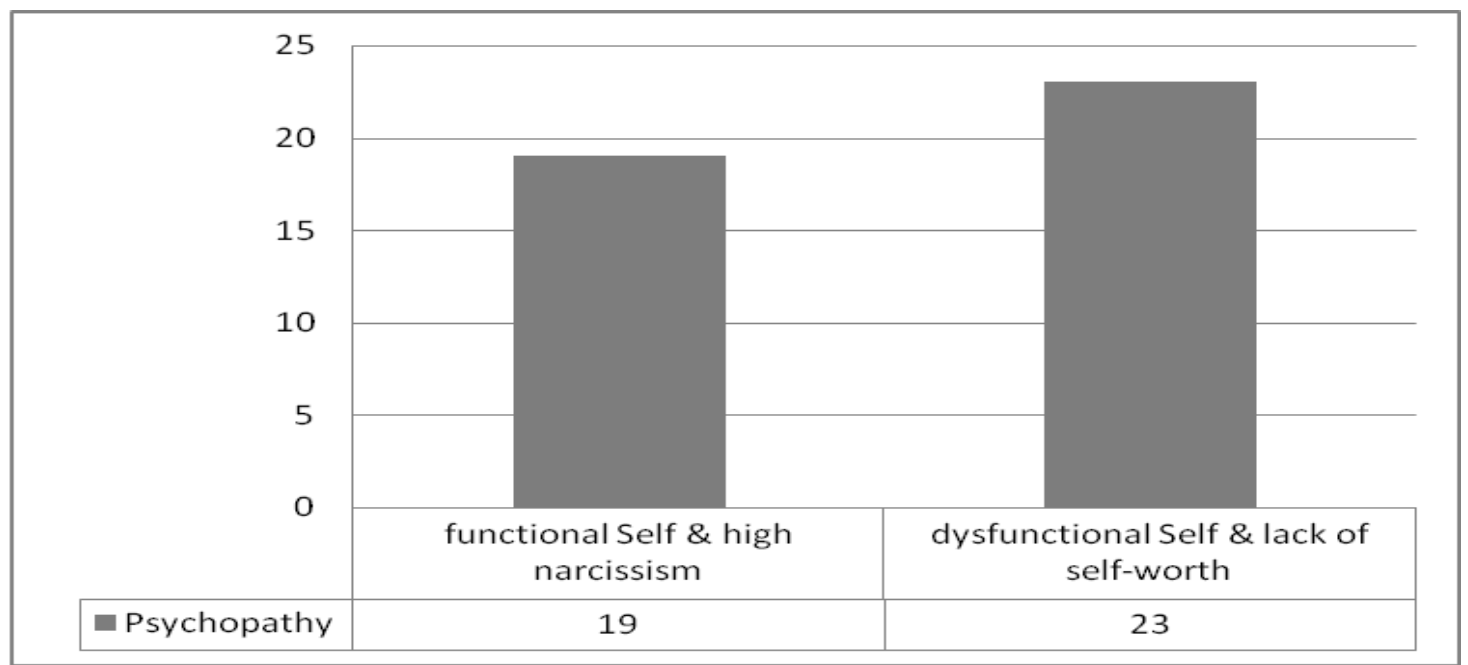

Figure 5.

The propensity for Psychopathy, depending on the type of narcissistic self-regulation.

Source: own research.

When the narcissistic self-regulation functions not well enough we can see the external emotional coldness, however, the internal emotional instability becomes more common. Apart from the fact that the tendency to respond "psychopathically" in certain situations may be useful for the subjective goals of the individual, we can see that it is combined with a low level of existential fulfillment. The tendency to focus on awards in social behavior (gaining) is also increasing. However, statistically higher indicators of this parameter show the greater destructiveness in interpersonal relations. So that can be assumed: such specific things may follow from the internationalized negative interactive experience and the struggle for the harmonious self-integration and self-value.

The earlier theoretical conclusion was confirmed in the current study: narcissistic self-regulation is a mechanism that takes care about the normal and healthy individual self-value, self-esteem and holistic self-representation, acts like the instrument of the integrity and the authentic perception of selfhoods and personal essence in the environment (Klymenko, 2018).

\section{Conclusions}

The connection between narcissistic self-regulation and personal selffulfillment, through the prism of self-value, was theoretically substantiated. The narcissistic self-regulation is the important condition of access to the world of external existential values and internal personal life-meanings, and is essential for the personal "Being" full of senses. The most distinct types of narcissistic self-regulation were analyzed. They differ in the level of effective execution of entrusted tasks: satisfaction of the body needs: "social needs, needs to be self-fulfilled; maintenance of the positive perception of one's Self and establishing a meaningful existence. The most functional type of narcissistic self-regulation (with a growing indicator of narcissism) is associated with a much more positive attitude towards life. It can be seen that the stabilizing 
function of narcissistic self-regulation cares about the emotional balance (with the predominance of emotional and appraisal attitude with rather «plus» sign), and this shows the integration of various vital experiences into the self-system.

The Narcissistic self-regulation is associated with the actualization of authentic individual existence. The Existence is manifested through it. As well as with the achievement of openness to the world and the capability to establish interchange with it. Thus the effective narcissistic self-regulation may support the realization of existential personal senses. Quoting A. Längle (2011, p. 43): "the existential task: the connection of the human being to life" performs more effectively. But in the case of its destructiveness and extreme strength of psychological protection (in the struggle for the self-integration) the reduction of self-worth, existential freedom, personal responsibility, and as a consequence, the life meaningfulness becomes possible.

The results of the study show that individuals with significant self-weakness and low self-value suffer from a considerable emptiness viewing the meaningful sense of their own existence. And summarizing: working with such people in the areas of psychological counseling, psychotherapy should be oriented towards psychological stabilization and the development of a reflexive culture, namely caring for a slightly fragile Self. This may be a significant prospect of further applied research.

\section{REFERENCES}

1. Bauman, Z. (2005). Индивидуализированное общество [The Individualized Society]. Moscow: Logos.

2. Bolotnikova, I. (2013). Цілісність особистості як чинник їі самоздійснення [Personal integrity as a factor of self-fulfillment]. Actual problems of psychology, 13, 40-47.

3. Deneke, F.W. (1994). Die Regulation des Selbsterlebens bei Gesunden, psychosomatischen, psychoneurotischen und alkoholkranken Patientenein taxonomischer Forschungsansatz. Psychotherapie, Psychosomatik und medizinische Psychologie, 44, 260-280.

4. Diener, E., Sandvik, E., Seidlitz L., Diener, M. (1993). The relationship between income subjective well-being: Relative or absolute?. Social Indicators Research, 28, 195-223.

5. Erikson, E. (1968). Identity: Youth and Crisis. New York: Norton.

6. Foster, J. D., Campbell, W. K. (2003). Individual differences in narcissism: Inflated self-views across the lifespan and around the world. Journal of Research in Personality, 37(6), 469-486.

7. Frankl, V. (2006). Man's Search for Meaning. An Introduction to Logotherapy. Boston: Beacon Press.

8. Freud, Z. (1914) Zur EinfÜHrung Des Narzissmus. Jb. Psychoan., 6, 1-24.

9. Gewirth, A. (1998). Self-Fulfillment. Princeton, N.J.: Princeton University Press.

10. Gulyas, I. (2011). Аксіопсихологічне проектування особистості: акмеорієнтований аспект [Axiopsychological design of personality: acmeorientated aspect]. Kharkiv National University Bulletin, 937, 60-64.

11. Horney, K. (1950). Neurosis and human growth. New York: Norton.

12. Kernberg, O. F. (2000). Тяжелые личностные расстройства: Cmратегии психотерапии [Severe personality disorders: Psychotherapeutic strategies]. Moscow: Klass.

13. Klein, M. (2002). Love, Guilt and Reparation: And Other Works 1921-1945. New York: Simon and Schuster.

14. Klymenko, M. (2018). Нарцисична саморегуляція особистісного самоздійснення [The narcissistic self-regulation of the personal fulfillment]. Psychology of personality, 1, 44-50.

15. Klymenko, M. (2017a). Особливості саморегуляції «здорового» нарцисизму [The "healthy" narcissistic self-regulation specifics]. Problems of modern psychology, 37, 142-155. 
16. Klymenko, M. (2017b). “Світло” нарцисизму в структурі “Темної тріади” [The light of narcissism in the Dark Triad structure]. Scientific journal of Kherson State University, Psychological science, 4, 58-64

17. Kohut, H. (1971). The analysis of the Self: Systematic Approach to Treatment of Narcissistic Personality Disorders. New York: International Universities Press.

18. Längle, A. (2002). Грандиозное одиночество. Нарциссизм как атропологически экзистенциальный феномен [The grandiosity of loneliness. Narcissism as an anthropologically existential phenomenon]. Moscow Psychotherapeutic Journal, 2, 34-58.

19. Längle, A. (2004). Введение в экзистенциально-аналитическую теорию эмоций: прикосновение к ценности [The introduction to Existential-Analytical Theory of Emotions: Touching Value]. Questions of psychology, 4, 3-21.

20. Längle, A., Orgler, C., Kundi, M. (2003). The Existence Scale. A new approach to assess the ability to find personal meaning in life and to reach existential fulfilment. European Psychotherapy, 4, 135-151.

21. Längle, A. (2014). From Viktor Frankl's Logotherapy to Existential Analytic psychotherapy. European Psychotherapy, 12, 67-837.

22. Längle, A., Trnka, R., Balcar, K., Kuska, M. (2011). Re-Constructing Emotional Spaces. From Experience to Regulation. Prague: Prague College of Psychosocial Studies Press.

23. May, R. (1953). Man's Search for Himself. New York: Bantam Doubleday Dell.

24. Morf, C., Rhodewalt, F. (2001). Unraveling the Paradoxes of Narcissism: A Dynamic Self-Regulatory Processing Mode. Psychological Inquiry, 12, 177-189.

25. Paulhus, D., Williams, K. (2002). The Dark Triad of personality: Narcissism, Machiavellianism and psychopathy. Journal of Research in Personality, 36 (6), 556-563.

26. Raskin, R., Terry, H. (1988). A Principal-Components Analysis of the Narcissistic Personality Inventory and Further Evidence of Its Construct Validity. Journal of Personality and Social Psychology, 54 (5), 890-902.

27. Titarenko, Т. (2008). Життєві завдання як практики самоконституювання особистості [Vital tasks as a practices of personal self-constitution]. Social Psychology, 6, 3-11.

28. Vasudha, S., Prasad, R. (2017). Narcissism, happiness and self-actualization. International Conference on Advances in Computing, Communications and Informatics, 2349-2358

29. Yalome, I. (1980). Existential Psychotherapy. New York: Basic Books. 